\title{
Different Biologic Grafts for Diaphragmatic Crura Reinforcement During Laparoscopic Repair of Large Hiatal Hernia: A Six-Year Single Surgeon Experience
}

\author{
Aleksandr A. Reznichenko
}

\begin{abstract}
Background: Large hiatal hernias represent a challenge for surgeons. Biologic grafts are currently popular for the strengthening of crural closure during laparoscopic repair. This study is a retrospective review of crural reinforcement in laparoscopic repair of large hiatal hernias using various biologic grafts performed by a single surgeon in a rural community hospital.
\end{abstract}

Methods: Eleven $(n=11)$ patients underwent laparoscopic repair of large hiatal hernia in a rural community hospital by a single surgeon from 2009 to 2015. Standard laparoscopic hiatal hernia repair was performed. Different biologic grafts were used for crural reinforcement, including "AlloMax", "Permacol", and "Acell MatriStem". Perioperative data and outcomes of surgery were evaluated.

Results: There were six females and five males, with a mean age of 55.4 years and a mean body mass index of 32.5. Eight patients had type III hiatal hernia, two patients had type IV, and one patient had type II. Mean operative time was 244.6 minutes, and mean length of stay was 3.3 days. Mean size of herniated stomach in the chest was $62 \%$. Mean size of the hiatal defect was $7.7 \times 6.4 \mathrm{~cm}$. One perioperative complication (9\%) included bleeding from left gastric artery. Early complications included shortness of breath (18\%), parapneumonic effusion (18\%), and early dysphagia (18\%). Late complications included persistent gastroesophageal reflux (9\%), gastroparesis $(9 \%)$, and persistent dysphagia (9\%). Radiological recurrence was $18 \%$ and clinical recurrence was $9 \%$ at mean follow-up of 15 months.

Conclusions: Laparoscopic repair of large hiatal hernia could be safely performed in rural community hospitals. The choice of the biologic graft, if one is used, should be at the discretion of the surgeon. The cost and availability of the biologic graft are important in decision-making.

Manuscript accepted for publication November 11, 2015

Division of Transplantation, Department of Surgery, University of Cincinnati, 231 Albert Sabin Way, Suite 1556, Cincinnati, OH 45267-0519, USA.

Email: areznik9@yahoo.com

doi: http://dx.doi.org/10.14740/jcs287w
Keywords: Laparoscopy; Large hiatal hernia; Hiatal hernia repair; Reinforcement of crural closure; Biologic mesh

\section{Introduction}

Minimally invasive approach in the repair of hiatal hernias became a standard of care during the last two decades. Laparoscopy offers faster recovery, shorter hospital stay, and less morbidity than traditional laparotomy [1]. Several studies have shown higher recurrence rates after a suture-based repair of hiatal hernias [2-4]. A "tension-free" repair with prosthetic mesh allowed decreasing recurrence [5], but the use of synthetic materials produced potentially serious problems, such as erosion and dysphagia [6-9]. Multiple reports showed reduction in short-term recurrence rate after hiatal hernia repair with biologic grafts [10-12]. However, the improvement in hiatal hernia recurrence decreased at long-term follow-up [13].

Biologic grafts used in hiatal hernia repairs are safe, and the incidences of mesh-related complications are low [10, 11, 13-16].

This is a study of various biologic grafts used for diaphragmatic crura reinforcement during laparoscopic repair of large hiatal hernias performed by a single surgeon in a rural community hospital.

\section{Materials and Methods}

A retrospective review was conducted on 11 patients who underwent laparoscopic repair of large hiatal hernia in a rural community hospital by a single general surgeon from 2009 to 2015. Only those hernias at least $6 \mathrm{~cm}$ in size (distance between right and left crus) and with $40 \%$ or more of the stomach herniated into the chest were included. This was determined by preoperative endoscopy, barium swallow study, computed tomography, and intraoperatively. Patient demographics, preoperative symptoms, body mass index (BMI), type and size of the hernia, operative times, length of stay, and intraoperative and postoperative complications were all evaluated. Follow-up data were examined to identify postoperative symptoms and improvement of quality of life, the presence of clinical or radiological recurrences, and mesh-related complications. 


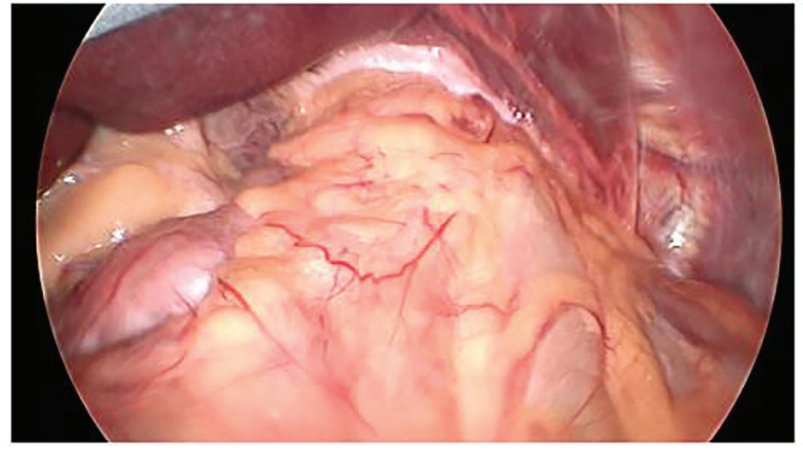

Figure 1. Type IV hiatal hernia with stomach and colon in the chest. Left lobe of the liver reflected cephalad.

\section{Surgical technique}

A standardized laparoscopic technique was utilized for all hiatal hernia repairs. There were no conversions to open procedure. All hernias were primary. There were no revisional surgeries. Five laparoscopic ports were used with the exception of one patient, who had BMI of 46. The positions of the ports were as follows: umbilical (5 or $10 \mathrm{~mm})$ as an optical port, right upper quadrant $(10 \mathrm{~mm})$ for retraction of the left lobe of the liver, three working ports ( $5 \mathrm{~mm}$ each) in the epigastric area, in the left upper quadrant and in the left mesogastrium. The left lobe of the liver was reflected cephalad with a Covidien $12 \mathrm{~mm}$ Endo Paddle Retract ${ }^{\mathrm{TM}}$ (Fig. 1). Five or $10 \mathrm{~mm}$ $30^{\circ}$ laparoscope was utilized. The diaphragmatic crura were opened from left to right. The short gastric vessels and the posterior gastric vessels to the base of the left crus were divided selectively, depending on the intraoperative findings. The hernia sac was dissected initially from the hiatus, followed by complete circumferential dissection from the mediastinal structures. Mediastinal lipomas were present in four patients. These were dissected and excised. The size of the herniation of the stomach into the chest was estimated based on both preoperative studies, and intraoperatively, after stomach was returned back to the intraabdominal cavity. Esophagus was dissected in the mediastinum as high as possible. Both vagus nerves were identified and preserved. Intraabdominal esophageal length of minimum $2.5 \mathrm{~cm}$ was accomplished with extensive mediastinal dissection; there was no need to perform

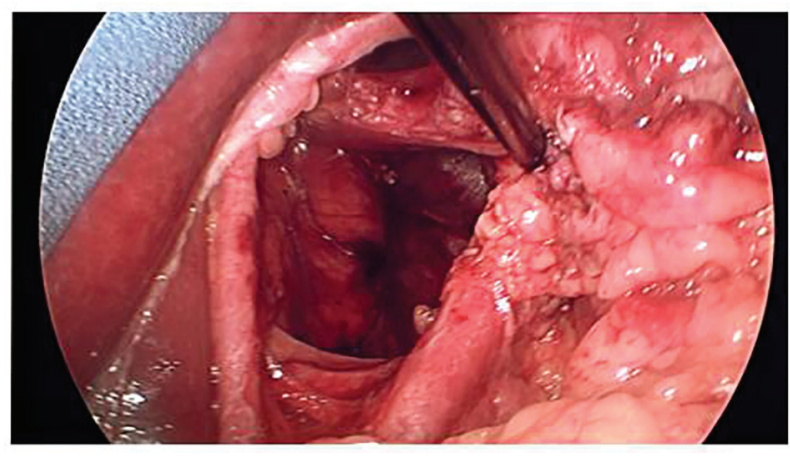

Figure 2. Large hiatal defect. Esophagus reflected to the left.

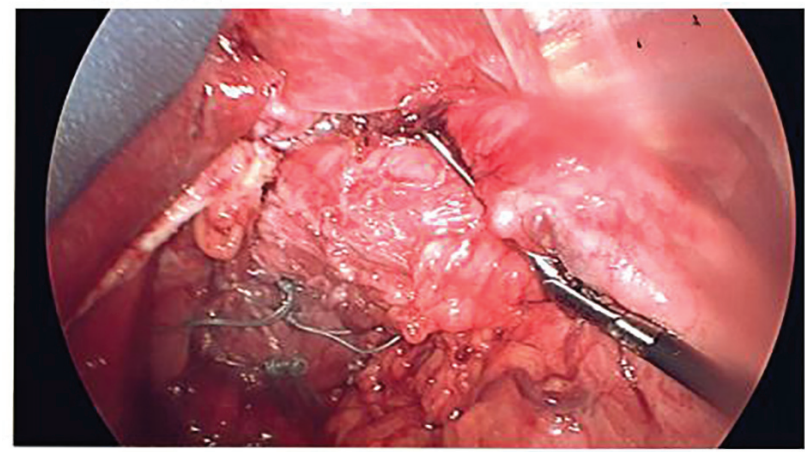

Figure 3. Cruroplasty.

vagotomy or Collis gastroplasty for the lengthening of the esophagus in this study. The size of the hernia was measured as a distance between right and left crus, and anterior to posterior distance between hiatal apex and posterior decussation of the right and left crura (Fig. 2). Posterior crural closure was performed with interrupted Ethibond endoknot sutures SKU EX10G (Ethicon Inc.) (Fig. 3). Additional anterior sutures were placed selectively on the crura depending on intraoperative situation.

The biologic graft for crural reinforcement was chosen based on the availability and the cost of the product. Three different types of graft were used, including acellular human dermal collagen (AlloMax ${ }^{\mathrm{TM}}$ ) in six patients, cellular porcine dermal implant $\left(\mathrm{Permacol}^{\mathrm{TM}}\right)$ in one patient, and porcine urinary bladder matrix (Acell MatriStem ${ }^{\circledR}$ ) in four patients. The size of the graft was either $10 \times 15 \mathrm{~cm}$ or $7 \times 10 \mathrm{~cm}$, depending on the size of the defect. After the graft was hydrated for 30 min, it was fashioned into "U" shape (with or without creation of a keyhole) and placed as an onlay patch posterior to the esophagus over the crural closure. Graft was secured to the diaphragm with hernia stapler (Fig. 4). ENDOPATH ${ }^{\circledR}$ EMS 10 $\mathrm{mm}$ Endoscopic stapler (Ethicon Inc.) was used for securing of AlloMax ${ }^{\mathrm{TM}}$ graft, ProTack Autosuture $5 \mathrm{~mm}$ stapler (Covidien Ltd) for Permacol ${ }^{\mathrm{TM}}$, and SECURESTRAP ${ }^{\circledR}$ Absorbable Fixation Device (Ethicon Inc.) for Acell MatriStem ${ }^{\circledR}$. Fundoplication performed in 10 out of 11 patients, using anterior Dor technique in eight patients, Nissen in one patient, and Toupet in one patient.

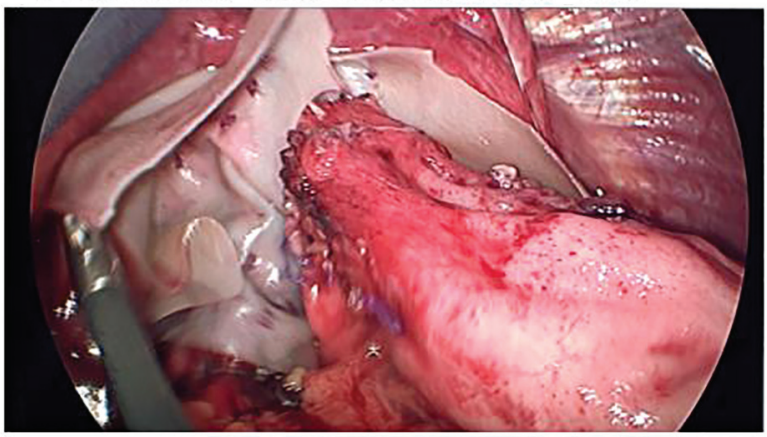

Figure 4. Crural reinforcement with onlay placement of Acell MatriStem ${ }^{\circledR}$ graft. 
Table 1. Demographics and Symptoms

\begin{tabular}{|c|c|c|c|c|c|c|c|c|c|c|c|}
\hline \multirow{2}{*}{$\begin{array}{l}\text { Patient } \\
\text { (n) }\end{array}$} & \multirow[b]{2}{*}{ Gender } & \multirow[b]{2}{*}{ BMI } & \multirow[b]{2}{*}{ Age } & \multicolumn{8}{|c|}{ Symptoms } \\
\hline & & & & $\begin{array}{l}\text { Epigastric } \\
\text { pain }\end{array}$ & $\begin{array}{l}\text { Chest } \\
\text { pain }\end{array}$ & SOB & Dysphagia & $\begin{array}{l}\text { Acid } \\
\text { reflux }\end{array}$ & $\begin{array}{l}\text { Nausea/ } \\
\text { vomiting }\end{array}$ & Hematemesis & $\begin{array}{l}\text { Weight } \\
\text { loss }\end{array}$ \\
\hline 2 & $\mathrm{~F}$ & 37 & 57 & Yes & Yes & No & Yes & Yes & No & No & No \\
\hline 3 & $\mathrm{~F}$ & 27 & 53 & Yes & Yes & Yes & Yes & No & No & No & No \\
\hline 6 & $\mathrm{~F}$ & 31 & 51 & No & Yes & Yes & Yes & Yes & No & No & yes \\
\hline 7 & $\mathrm{~F}$ & 34 & 42 & Yes & Yes & No & No & Yes & No & No & No \\
\hline 8 & M & 28 & 49 & No & No & Yes & Yes & No & No & No & No \\
\hline 9 & M & 24 & 45 & No & Yes & No & Yes & No & No & No & No \\
\hline
\end{tabular}

BMI: body mass index; SOB: shortness of breath.

\section{Results}

Eleven patients underwent laparoscopic repair of large hiatal hernias with the reinforcement of the crural closure with biologic graft. There were six females and five males, with a mean age of $55.4 \pm 8.7$ years and a mean BMI of $32.5 \pm 7.5$. Chest pain was the most common symptom (91\%), followed by dysphagia (82\%), epigastric abdominal pain and heartburn (64\% each), shortness of breath (55\%), nausea and vomiting (4\%), hematemesis (2\%), and weight loss (1\%) (Table 1). Preoperative evaluation included esophagogastroduodenoscopy in eight patients, computed tomography in all patients, and upper gastrointestinal study in nine patients. Mean operative time was $244.6 \pm 71.7 \mathrm{~min}$, and mean length of stay was $3.3 \pm 1.8$ days. Six patients had the reinforcement of the crura with AlloMax ${ }^{\mathrm{TM}}$, one patient with Permacol $^{\mathrm{TM}}$, and four patients with Acell MatriStem ${ }^{\circledR}$. In all cases, right and left crura were approximated. Three patients were operated under the urgent settings, with suspected diagnosis of gastric volvulus, based on clinical presentation and radiological findings. There was no evidence of acute gastric ischemia intraoperatively. The average size of herniated stomach in the chest was $62 \pm 22.7 \%$, with entire stomach herniated inside the chest in two patients. Eight patients had type III hiatal hernia, two patients had type IV, and one patient had type II. Two patients with type IV hiatal hernia had colon together with stomach in the chest (Fig. 5). Secondary procedure was performed in three patients along with hiatal hernia repair, including laparoscopic cholecystectomy in two patients, and umbilical hernia repair in one patient. Mean sizes of the hiatal defect were $7.7 \pm 1.1 \mathrm{~cm}$ (right to left) and $6.4 \pm 0.8 \mathrm{~cm}$ (anterior to posterior). Only one perioperative complication (9\%) was encountered and included bleeding from left gastric artery in a morbidly obese patient (BMI 46) with estimated blood loss of $500 \mathrm{~mL}$. Average intraoperative blood loss was $65 \pm 145.4 \mathrm{~mL}$ (Table 2).

Postoperatively all patients were kept on national dysphagia level II diet for 4 weeks, with subsequent slow transition to regular diet within 6 - 8 weeks. Clinical follow-up ranged from 3 to 40 months. All patients were evaluated with standard questionnaire; during the interviews, they were asked about the existence and/or persistence of their symptoms. An objective score test, the gastrointestinal quality of life index (GIQLI), was also administered. All 11 patients noticed disappearance of epigastric pain, chest pain, nausea and vomiting, hematemesis, and weight loss. Early symptoms and complications included shortness of breath in two patients $(18 \%)$,

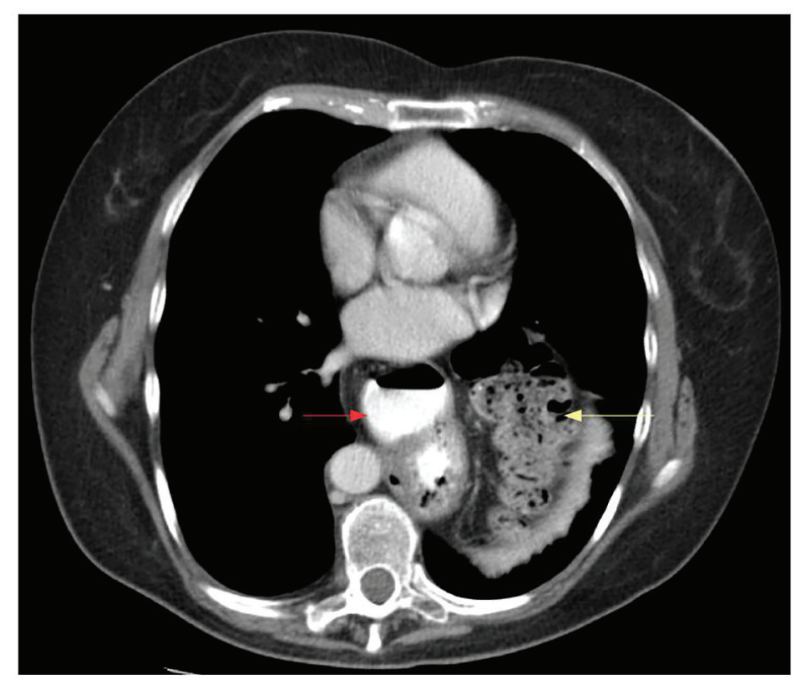

Figure 5. Computed tomography axial view of stomach (red arrow) and colon (yellow arrow) in the chest. 


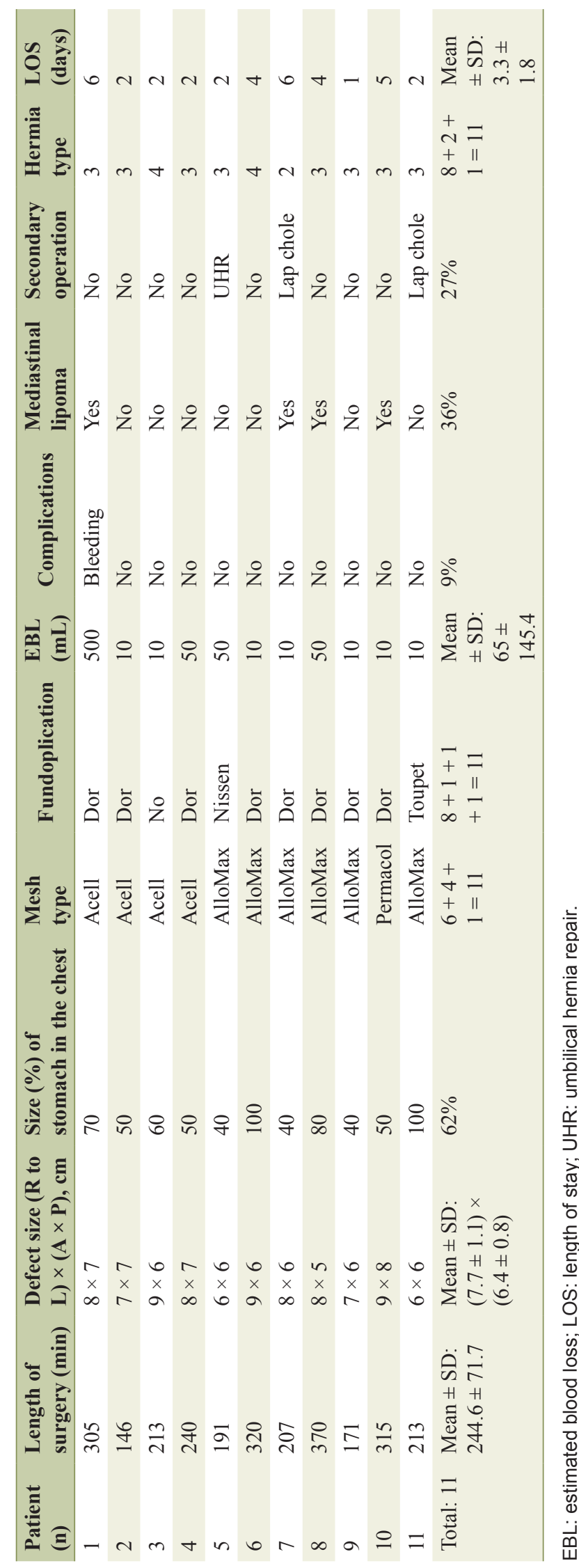

parapneumonic effusion in two patients $(18 \%)$, and early dysphagia in two patients (18\%). These complications completely resolved in within 3 - 4 weeks postoperatively. One patient with parapneumonic effusion required one-time aspiration by interventional radiology.

Late complications included persistent gastroesophageal reflux in one patient $(9 \%)$, gastroparesis in one patient $(9 \%)$, and persistent dysphagia in one patient $(9 \%)$. A patient with persistent gastroesophageal reflux during 6 months follow-up had no other symptoms, and was satisfied with surgery and quality of life. The severity of acid reflux after surgery decreased and the patient was successfully treated with proton pump inhibitors. Computed tomography was performed for other indications and showed a small recurrent paraesophageal hernia.

One patient experienced abdominal bloating and early satiety, and was diagnosed with gastroparesis. This patient had the most technically challenging and time consuming operation (among all 11 patients in this study) secondary to severe dense adhesions of large hernia sac to the mediastinal structures. Patient was treated successfully with dopamine-receptor antagonist, and showed no evidence of recurrence at the 24 months follow-up.

One patient with persistent dysphagia was diagnosed with recurrent hiatal hernia at 6 months follow-up. This patient underwent esophagogastroscopy, which showed stricture in the distal esophagus. Balloon dilatation of the stricture was performed with improvement, but no complete resolution of dysphagia.

Seven patients $(64 \%)$ underwent radiological evaluation postoperatively within 6 - 24 months follow-up. Two patients (18\%) underwent esophagogastroscopy. Among 11 patients in this study, one had clinical recurrence $(9 \%)$, and two had radiological recurrence (18\%) (Table 3).

\section{Discussion}

Laparoscopic approach became a standard of care for the repair of hiatal hernias because it offers faster recovery, shorter hospital stay, and less morbidity than traditional open approach [1]. Operative steps in the laparoscopic hiatal hernia repair include reduction of the stomach from mediastinum, dissection of the hernia sac away from mediastinal structures, return of gastroesophageal junction to an infradiaphragmatic position ensuring an appropriate (at least $2-3 \mathrm{~cm}$ ) intraabdominal length of the esophagus, primary crural closure, and fundoplication [1]. There is no consensus regarding fundoplication during repairs of large hiatal hernias [2, 17]. Fundoplication was not performed on only one patient in this study; this patient with type IV hiatal hernia presented with severe dysphagia, and did not have acid reflux. Patient has no clinical and/or radiological recurrence and no evidence of acid reflux during 12 months follow-up.

Esophageal lengthening procedures were not performed in this study. It was felt that high esophageal mobilization in the mediastinum was sufficient to achieve at least $2.5 \mathrm{~cm}$ of intraabdominal length of the esophagus. Mediastinal lipomas were encountered in four patients and were excised. 


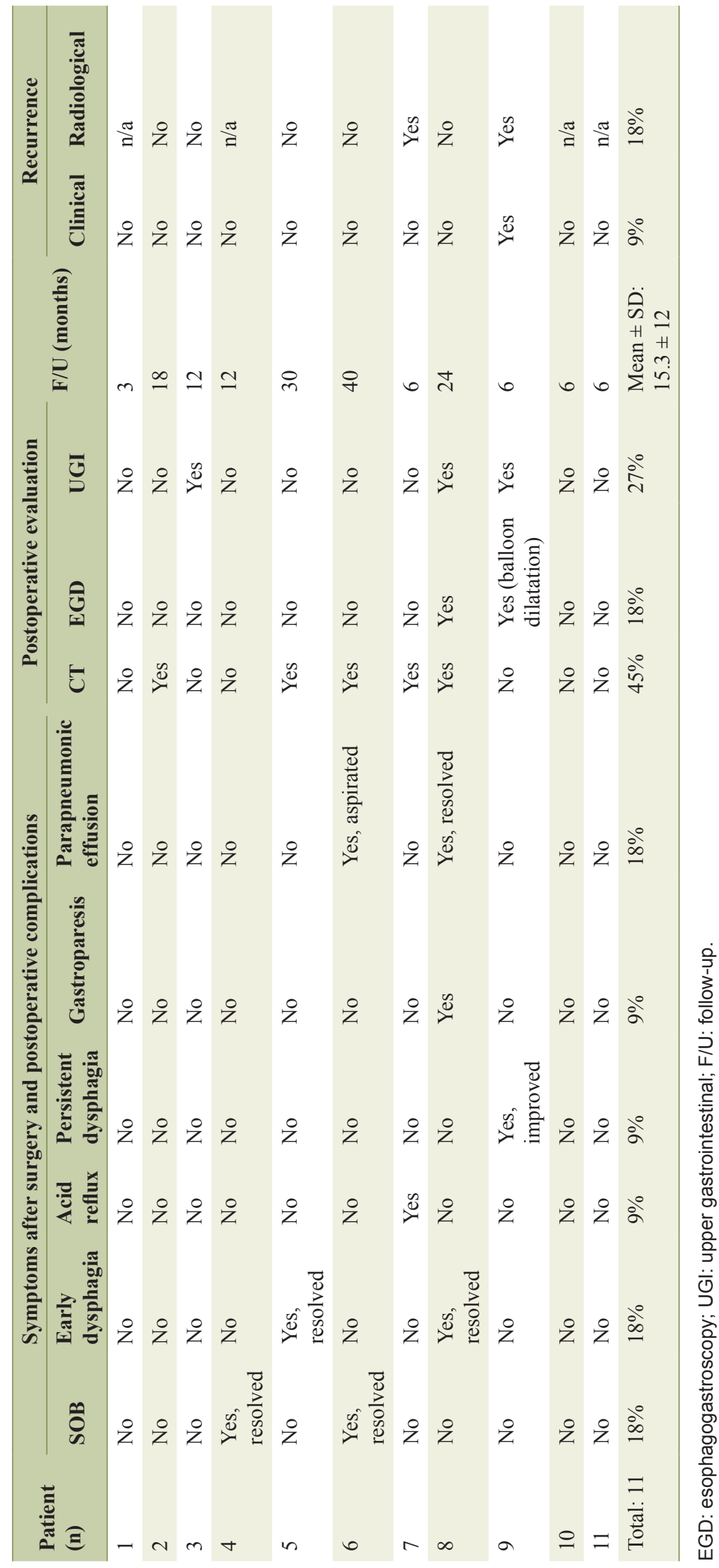


Controversy exists around the reinforcement of the diaphragmatic crura, as well as the type of the graft used, and the value of the graft in preventing recurrence, around short- and long-term complications, and the consequences of those complications compared with primary repair [14].

Higher recurrence rates were reported after suture-based laparoscopic repair of hiatal hernia [2-4]. Two prospective, randomized clinical trials have shown that "tension-free" laparoscopic hernia repair with prosthetic graft prevents recurrence $[5$, 6]. However, use of synthetic materials for crural reinforcement produced potentially serious problems, such as erosion and dysphagia [6-9]. This leads to popularization of biological grafts.

After initial enthusiasm in reduction of short-term recurrence rates [10-12], the benefit of biologic grafts in improving hiatal hernia recurrence decreased at long-term followups. A multicenter prospective, randomized trial showed no significant difference in relevant symptoms or quality of life between patients undergoing primary laparoscopic hiatal hernia repair and small intestinal submucosa (SIS) buttressed repair. The recurrence rate after repair with biological graft approached 54\% at median follow-up of 58 months [13]. We had a radiological recurrence rate of $18 \%$ at mean follow-up of 15 months; however, only seven out of 11 patients had imaging studies postoperatively. Two patients failed to follow-up after 6 months, one patient refused to have an imaging study, and another patient had just recently undergone hiatal hernia repair. All of these patients were satisfied with operation and quality of life, and have not had a clinical recurrence of hiatal hernia.

The safety of biologic graft in hiatal hernia repairs was emphasized in several published series, and the incidence of graft-related complications and side effects were low [10, 11, 13-16]. There were no graft-related complications noticed throughout this study.

Despite the disappointingly high radiological recurrence rates in recent series $[13,17,18]$, laparoscopic repair of hiatal hernias with biologic graft has shown an excellent long-term quality of life $[19,20]$. There was a clinical recurrence rate of $9 \%$ in this study at 15 months follow-up. Persistent gastroesophageal reflux in one patient and gastroparesis in another were managed conservatively with success. One patient with recurrent hernia and persistent dysphagia underwent esophagogastroscopy which showed stricture in the distal esophagus. Balloon dilatation was performed with improvement, but no complete resolution of dysphagia.

Recent multicenter randomized controlled trial showed no difference in the outcome between primary repair, repair with synthetic mesh and repair with biologic graft. At the same time, the quality of life improved significantly after all types of hernia repair [21]. According to the most recent reviews, either mesh repair or primary repair may be the treatment of choice, based on the decision made by individual surgeons, and depending on their own recurrence and reoperation rates [14]. With regard to the choice of mesh, it should also be at the discretion of the surgeon based on his/her experience. The choice of the graft in this study was made based not only on the preference of the surgeon, but also on the availability and the cost of the product. It is important to emphasize that the cost became a significant important factor for the decision-making due to current condition of the health care system, particularly in the settings of rural community hospitals. Three different types of biologic graft were used, including acellular human dermal collagen (AlloMax ${ }^{\mathrm{TM}}$ ) in six patients, cellular porcine dermal implant (Permacol ${ }^{\mathrm{TM}}$ ) in one patient, and porcine urinary bladder matrix (Acell MatriStem ${ }^{\circledR}$ ) in four patients.

AlloMax ${ }^{\mathrm{TM}}$ Surgical Graft (Bard Davol Inc.) is an acellular non-cross-linked human dermis allograft. Several studies have shown success in using AlloMax ${ }^{\mathrm{TM}}$ for breast reconstruction [22], ventral hernia repair [23], and hiatal hernia repair [16].

Permacol $^{\mathrm{TM}}$ (Covidien Ltd.) is xenogeneic and composed of cross-linked porcine dermal collagen. Permacol ${ }^{\mathrm{TM}}$ was shown to be safe with relatively low rates of recurrence in repair of ventral and incisional hernias [24], and large complex abdominal wall hernias [25]. There were few reports of using Permacol $^{\mathrm{TM}}$ in large diaphragmatic hernias $[26,27]$.

Acell MatriStem ${ }^{\circledR}$ (Acell Inc.) is an extracellular matrix scaffold composed of the decellularized epithelial basement membrane and lamina propria of the porcine urinary bladder. Acell MatriStem ${ }^{\circledR}$ was successfully used in the treatment of difficult non-healing radiated wounds [28] and complex pilonidal wounds [29]. One recent study has shown that the use of urinary bladder matrix may be helpful in decreasing the incidence of esophagojejunal anastomotic leak and/or stricture after total gastrectomy [30].

All biologic grafts in this study were hydrated for $30 \mathrm{~min}$, fashioned into "U" shape, and placed as an onlay patch posterior to the esophagus over the crural closure. All products were easy to work with. Hernia staplers were used to secure the grafts to the diaphragm. Acell MatriStem ${ }^{\circledR}$ graft was secured with absorbable tacks, which were less traumatic compared to permanent titanium tacks. Acell MatriStem ${ }^{\circledR}$ graft had a little higher pliability. However, it should be emphasized that this reflects only an individual surgeon opinion.

There were no differences between various types of grafts in this study with regard to operative time, length of stay, and complications. Two of the recurrences occurred in patients with Allomax ${ }^{\mathrm{TM}}$ graft. However, these data are not sufficient enough to conclude that one product was superior to the other.

In conclusion, laparoscopic repair of large hiatal hernias is a challenging and complex procedure. When all the principles are followed, this operation could be effectively and safely performed in rural hospitals. The choice of the repair and mesh, if the one is used, is up to the individual surgeon. The cost and availability of the biologic graft are important in decision-making.

\section{Acknowledgement}

The author wants to thank Philip L. Leggett, M.D, F.A.C.S, Houston Northwest Medical Center, TX.

\section{Disclosures}

No. 


\section{Conflict of Interest}

The author declares no conflict of interest.

\section{References}

1. Kohn GP, Price RR, DeMeester SR, Zehetner J, Muensterer OJ, Awad Z, Mittal SK, et al. Guidelines for the management of hiatal hernia. Surg Endosc. 2013;27(12):44094428.

2. Hashemi M, Peters JH, DeMeester TR, Huprich JE, Quek M, Hagen JA, Crookes PF, et al. Laparoscopic repair of large type III hiatal hernia: objective followup reveals high recurrence rate. J Am Coll Surg. 2000;190(5):553560; discussion 560-551.

3. Diaz S, Brunt LM, Klingensmith ME, Frisella PM, Soper NJ. Laparoscopic paraesophageal hernia repair, a challenging operation: medium-term outcome of 116 patients. J Gastrointest Surg. 2003;7(1):59-66; discussion 66-57.

4. Mattar SG, Bowers SP, Galloway KD, Hunter JG, Smith $\mathrm{CD}$. Long-term outcome of laparoscopic repair of paraesophageal hernia. Surg Endosc. 2002;16(5):745-749.

5. Frantzides CT, Madan AK, Carlson MA, Stavropoulos GP. A prospective, randomized trial of laparoscopic polytetrafluoroethylene (PTFE) patch repair vs simple cruroplasty for large hiatal hernia. Arch Surg. 2002;137(6):649652.

6. Granderath FA, Kamolz T, Schweiger UM, Pointner R. Impact of laparoscopic nissen fundoplication with prosthetic hiatal closure on esophageal body motility: Results of a prospective randomized trial. Arch Surg. 2006;141(7):625-632.

7. Hazebroek EJ, Leibman S, Smith GS. Erosion of a composite PTFE/ePTFE mesh after hiatal hernia repair. Surg Laparosc Endosc Percutan Tech. 2009;19(2):175-177.

8. Fenton-Lee D, Tsang C. A series of complications after paraesophageal hernia repair with the used of Timesh: a case report. Surg Laparose Endosc Percutan Tech. 2010;20(3):e95-96.

9. Arroyo Q, Arguelles-Arias F, Jimenez-Saenz M, Herrerias-Gutierrez JM, Pellicer Bautista F, Rodriguez-Tellez M. Dysphagia caused by migrated mesh after paraesophageal hernia repair. Endoscopy. 2011;43 Suppl 2 UCTN:E257-258.

10. Oelschlager BK, Pellegrini CA, Hunter J, Soper N, Brunt M, Sheppard B, Jobe B, et al. Biologic prosthesis reduces recurrence after laparoscopic paraesophageal hernia repair: a multicenter, prospective, randomized trial. Ann Surg. 2006;244(4):481-490.

11. Diaz DF, Roth JS. Laparoscopic paraesophageal hernia repair with acellular dermal matrix cruroplasty. JSLS. 2011;15(3):355-360.

12. Lee E, Frisella MM, Matthews BD, Brunt LM. Evaluation of acellular human dermis reinforcement of the crural closure in patients with difficult hiatal hernias. Surg Endosc. 2007;21(4):641-645.

13. Oelschlager BK, Pellegrini CA, Hunter JG, Brunt ML,
Soper NJ, Sheppard BC, Polissar NL, et al. Biologic prosthesis to prevent recurrence after laparoscopic paraesophageal hernia repair: long-term follow-up from a multicenter, prospective, randomized trial. J Am Coll Surg. 2011;213(4):461-468.

14. Obeid NM, Velanovich V. The choice of primary repair or mesh repair for paraesophageal hernia: a decision analysis based on utility scores. Ann Surg. 2013;257(4):655664.

15. Wassenaar EB, Mier F, Sinan H, Petersen RP, Martin AV, Pellegrini CA, Oelschlager BK. The safety of biologic mesh for laparoscopic repair of large, complicated hiatal hernia. Surg Endosc. 2012;26(5):1390-1396.

16. Alicuben ET, Worrell SG, DeMeester SR. Resorbable biosynthetic mesh for crural reinforcement during hiatal hernia repair. Am Surg. 2014;80(10):1030-1033.

17. Linke GR, Gehrig T, Hogg LV, Gohl A, Kenngott H, Schafer F, Fischer L, et al. Laparoscopic mesh-augmented hiatoplasty without fundoplication as a method to treat large hiatal hernias. Surg Today. 2014;44(5):820-826.

18. Jones R, Simorov A, Lomelin D, Tadaki C, Oleynikov D. Long-term outcomes of radiologic recurrence after paraesophageal hernia repair with mesh. Surg Endosc. 2015;29(2):425-430.

19. Lidor AO, Steele KE, Stem M, Fleming RM, Schweitzer MA, Marohn MR. Long-term quality of life and risk factors for recurrence after laparoscopic repair of paraesophageal hernia. JAMA Surg. 2015;150(5):424-431.

20. Targarona EM, Grisales S, Uyanik O, Balague C, Pernas JC, Trias M. Long-term outcome and quality of life after laparoscopic treatment of large paraesophageal hernia. World J Surg. 2013;37(8):1878-1882.

21. Koetje JH, Irvine T, Thompson SK, Devitt PG, Woods SD, Aly A, Jamieson GG, et al. Quality of Life Following Repair of Large Hiatal Hernia is Improved but not Influenced by Use of Mesh: Results From a Randomized Controlled Trial. World J Surg. 2015;39(6):1465-1473.

22. Farias-Eisner GT, Small K, Swistel A, Ozerdem U, Talmor M. Immediate implant breast reconstruction with acellular dermal matrix for treatment of a large recurrent malignant phyllodes tumor. Aesthetic Plast Surg. 2014;38(2):373-378.

23. Roth JS, Brathwaite C, Hacker K, Fisher K, King J. Complex ventral hernia repair with a human acellular dermal matrix. Hernia. 2015;19(2):247-252.

24. Chand B, Indeck M, Needleman B, Finnegan M, Van Sickle KR, Ystgaard B, Gossetti F, et al. A retrospective study evaluating the use of Permacol surgical implant in incisional and ventral hernia repair. Int J Surg. 2014;12(4):296-303.

25. Satterwhite TS, Miri S, Chung C, Spain DA, Lorenz HP, Lee GK. Abdominal wall reconstruction with dual layer cross-linked porcine dermal xenograft: the "Pork Sandwich" herniorraphy. J Plast Reconstr Aesthet Surg. 2012;65(3):333-341.

26. Gooch B, Smart N, Wajed S. Transthoracic repair of an incarcerated diaphragmatic hernia using hexamethylene diisocyanate cross-linked porcine dermal collagen (Permacol). Gen Thorac Cardiovasc Surg. 2012;60(3):145- 
148.

27. Lingohr P, Galetin T, Vestweber B, Matthaei H, Kalff JC, Vestweber KH. Conventional mesh repair of a giant iatrogenic bilateral diaphragmatic hernia with an enterothorax. Int Med Case Rep J. 2014;7:23-25.

28. Rommer EA, Peric M, Wong A. Urinary bladder matrix for the treatment of recalcitrant nonhealing radiation wounds. Adv Skin Wound Care. 2013;26(10):450-455.
29. Sasse KC, Brandt J, Lim DC, Ackerman E. Accelerated healing of complex open pilonidal wounds using MatriStem extracellular matrix xenograft: nine cases. J Surg Case Rep. 2013;2013(4).

30. Afaneh C, Abelson J, Schattner M, Janjigian YY, Ilson D, Yoon SS, Strong VE. Esophageal reinforcement with an extracellular scaffold during total gastrectomy for gastric cancer. Ann Surg Oncol. 2015;22(4):1252-1257. 